\title{
HUBUNGAN TUGAS PMO DALAM MENGINGATKAN PERIKSA DAHAK DENGAN KEJADIAN DROP OUT (DO) PENGOBATAN TUBERKULOSIS
}

\author{
Nina Pamela Sari ${ }^{1}$, Gandi Sukma Nugraha ${ }^{2}$

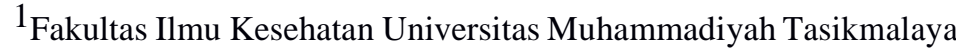 \\ Email : ninapamelasari@gmail.com \\ ${ }^{2}$ Fakultas Ilmu Kesehatan Universitas Muhammadiyah Tasikmalaya \\ Email : nina.pamelasari@umtas.ac.id
}

\begin{abstract}
ABSTRAK
Latar belakang: Tuberculosis (TB) sampai saat ini masih menjadi masalah utama kesehatan di dunia. Dalam program pemberantasan penyakit TB masih adanya kejadian drop out (DO) pengobatan TB. TB di Indonesia menjadi penyebab kematian nomor dua setelah stroke. Angka kematian akibat TB dipengaruhi oleh gagalnya pengobatan atau DO. Tugas PMO selain mendampingi pasien menjalani pengobatan TB juga mengingatkan periksa dahak sebagai pengawasan perkembangan pengobatan pasien TB.Tujuan penelitian ini adalah untuk mengetahui pelaksanaan tugas PMO (Pengawas Menelan Obat) dalam mengingatkan periksa dahak dengan kejadian drop out (DO) pengobatan TB di wilayah kerja puskesmas Tamansari Kota Tasikmalaya.Metode penelitian : metode analitik menggunakan rancangan retrospektif dengan pendekatan case control. Populasi terdiri dari populasi kasus yaitu penderita TB yang DO dan populasi kontrol yaitu penderita TB yang tidak DO. Sampel yang diambil terdiri dari sampel kasus 56 orang dan sampel kontrol 56 orang diperoleh dengan menggunakan teknik simple random sampling. Instrumen yang digunakan adalah kuesioner. Data yang diperoleh dalam penelitian ini dianalisis uji Chi Square dengan p value 0,05 dan menghitung nilai Odds Ratio (OR).Hasil : Dari hasil penelitian dapat disimpulkan bahwa faktor pelaksanaan tugas PMO dalam mengingatkan periksa dahak berhubungan signifikan dengan DO pengobatan TB. ( $p$ value=0.018, OR=2.600). Saran : Berdasar hasil penelitian ini diharapkan dapat sebagai dasar peningkatan kinerja dari petugas programer TB dan PMO dalam meningkatkan kesadaran penderita TB dalam kepatuhan pengobatan.
\end{abstract}

Kata Kunci : Tuberculosis (TB), tugas PMO, periksa dahak, drop out TB.

\begin{abstract}
Background: Tuberculosis $(T B)$ is still a major health problem in the world. In the TB eradication program there are still cases of TB treatment drop out $(D O)$. TB in Indonesia is the number two cause of death after a stroke. The death rate from TB is affected by the failure of treatment or DO. The task of the observer in addition to assisting patients undergoing TB treatment also warns that sputum checks are monitoring the development of treatment for TB patients. The purpose : of this study was to determine the implementation of the tasks of the observer in reminding sputum checks with the incidence of drop out (DO) TB treatment in the working area of Tamansari City of Tasikmalaya.Research method: analytical method using a retrospective design with a case control approach. The population consisted of case populations, namely DO patients with TB and control populations, namely TB patients who did not DO. The sample taken consisted of a sample of 56 people and a control sample of 56 people obtained using a simple random sampling
\end{abstract}


technique. The instrument used was a questionnaire. The data obtained in this study were analyzed by Chi Square test with p value 0.05 and calculating the value of Odds Ratio (OR). Results: From the results of the study it can be concluded that the factors implementing observer tasks in reminding sputum check were significantly associated with DO TB treatment. ( $p$ value $=0.018, O R=2,600$ ). Suggestion: Based on the results of this study, it is expected to be a basis for improving the performance of TB programmers and observer in raising awareness of TB patients in treatment compliance.

Keywords : Tuberculosis (TB), observer task, sputum check, drop out TB.

\section{PENDAHULUAN}

Tuberkulosis (TB) merupakan salah satu masalah kesehatan bagi bangsa Indonesia dan dunia, penyakit ini disebabkan oleh mycrobacterium tuberculosis, dan dapat menular dengan perantara percikan dahak dari penderita TB melalui udara. (Kemenkes, 2014). Menurut laporan WHO 2015 kasus TB di Indonesia diperkirakan terdapat 1 juta kasus TB baru pertahun (399 per 100.000 penduduk) dengan 100.000 angka kematian pertahun (41 per 100.000) angka CNR (case notofocation rate) dari semua kasus, didapatkan sebanyak 129 per 100.000 penduduk (Permenkes RI No 67, 2016). Tingginya angka kesakitan dan kematian akibat TB Paru sehingga WHO merekomendasikan rencana untuk menanggulanginya melalui DOTS sebagai pengendalian
TB, selain itu pemerintah juga menetapkan program Pemberantasan Penyakit Tuberculosis ( P2TB) yang salah satunya adalah PMO (Pengawas Minum Obat) yaitu dengan pengawasan secara langsung kepada penderita TB Paru agar meminum obat secara teratur selama 6 bulan. (Kemenkes RI, dalam PNPT 2014).

Di Kota Tasikmalaya pada tahun 2012 tercatat ada 1,027, kasus dengan BTA positif kasus baru sebanyak $75.35 \%$ per 100.000 penduduk, dan angka success rate mencapai 88,60\% telah mencapai target yang tetapkan yakni minimal $85 \%$ (Profil Kesehatan Jawa Barat, 2012).

Berdasarkan laporan tahun 2015 di Kota Tasikmalaya seluruh penderita yang didiagnosis TB paru mencapai 1182 jiwa dengan kasus BTA positif dan BTA negatif pada tahun 2015 juga jumlah kasus DO mencapai 124 jiwa atau $14 \%$ yang DO sudah 
melebihi nilai minimum angka DO yang di tetapkan yakni $5 \%$ dari total seleruh penderita pada tahun tersebut (Dinkes Kota Tasikmalaya, 2017).

Hasil studi pendahuluan yang di lakukan pada tanggal 5 Mei 2017 di Puskesmas Tamansari dan Puskesmas Sangkali, terdapat 8 pasien dengan status DO pada tahun 2016. Dari keterangan petugas puskesmas dikatakan bahwa pasien tersebut DO dikarenakan kurangnya kesadaran untuk bisa sembuh walaupun sudah di ingatkan oleh petugas puskesmas agar bisa berobat tuntas serta peran dan fungsi dari PMO yang masih belum maksimal untuk mengingatkan penderita TB agar teratur dalam minum obat juga mengingatkan pasien TB untuk periksa dahak sebagai salah satu indikator keberhasilan pengobatan TB. Menurut programer TB, PMO di Kota Tasikmalaya maupun di Kabupaten Tasikmalaya masih belum di evaluasi, hasil dari observasi terhadap petugas kesehatan juga dikatakan bahwa pasien mengambil obat TB dengan datang sendiri ke puskesmas tanpa didampingi oleh PMO. Agar tugas PMO tersebut dapat meningkatkan keberhasilan pengobatan dari penderita TB maka perlu diketahui hubungan tugas PMO dalam mengingatkan periksa dahak dengan kejadian Drop Out TB di Puskesmas Tamansari Kota Tasikmalaya.

\section{METODE PENELITIAN}

Rancangan penelitian yang digunakan dalam penelitian ini adalah metode analitik menggunakan rancangan penelitian retrospektif dengan pendekatan case control. Jenis penelitian Retrospektif artinya penelitian yang berusaha melihat ke belakang (backward looking), pengumpulan data dimulai dari efek atau akibat yang telah terjadi kemudian dicari penyebabnya atau variabel yang mempengaruhi akibat tersebut, desain penelitian case control. Dengan pendekatan ini peneliti mengetahui hubungan pelaksanan tugas PMO dalam mengingtakan periksa dahak terhadap kejadian Drop Out pengobatan TB di wilayah kerja Puskesmas Kota Tasikmalaya.

Populasi kasus Populasi kasus pada penelitian ini adalah semua PMO 
Nina Pamela Sari, Gandi Sukma Nugraha "'Hubungan Tugas Pmo Dalam Mengingatkan Periksa Dahak Dengan Kejadian Drop Out (Do) Pengobatan Tuberkulosis" (hal 176-184)

dengan pasien Drop Out pengobatan

TB sebanyak 98 jiwa pada tahun 2016.

Populasi kontrol Populasi kontrol adalah semua PMO dengan penderita yang sembuh di wilayah kerja Puskesmas Kota Tasikmalaya sebanyak 98 orang.

Untuk memudahkan peneliti sampel dalam penelitian ini diperoleh berdasarkan perhitungan odds di tabel dengan kasus tidak berpajanan dua arah. Perbandingan kasus dengan control yaitu 1:1 dengan $\alpha=0.05, \beta=$ 0.20 , P (proporsi pajanan ) $0.30 \mathrm{di}$ dapat dari hasil penelitian Naili (2010) dengan variabel faktor PMO, dan odss ratio 3 didapatkan sampel sebanyak 56 orang.

Teknik pengambilan sampel dalam penelitian ini dilakukan dengan metode simple random sampling secara undian. Jadi semua populasi kasus yang drop out dipilih secara undian, dengan memasukan namanama pasien yang drop out dengan cara menuliskan 98 namanya kemudian diambil sebanyak 56 nama diambil dengan cara dikocok begitu pula dengan sampling pada control yaitu pasien TB yang melakukan pengobatan secara tuntas. Tempat penelitian adalah Unit Pelayanan Kesehatan Puskesmas di Wilayah Kota Tasikmalaya. Kuesioner dalam penelitian ini telah di uji konten dengan programer TB Dinas Kesehatan Kabupaten Tasikmalaya untuk melihat validitas dari pertanyaan dalam kuesioner di cross check pertanyaan inti antara PMO dengan penderita TB.

Untuk mengetahui estimasi risiko relative dihitung dengan odds ratio (OR) dengan table 2x2. OR menunjukkan besarannya peran factor resiko yang diteliti terhadap penyakit (efek). Hipotesa penelitan adalah ada hubungan faktor PMO dalam mengingatkan periksa dahak terhadap kejadian Drop Out pengobatan TB di Wilayah Kerja Puskesmas Kota Tasikmalaya.

\section{HASIL DAN PEMBAHASAN}

Tabel 1.1 Hubungan Antara Faktor $\begin{array}{lll}\text { Pelaksanaan Tugas } & \text { PMO }\end{array}$ Mengingatkan Periksa Dahak Dengan Kejadian Drop Out Pengobtan TB 
Nina Pamela Sari, Gandi Sukma Nugraha "Hubungan Tugas Pmo Dalam Mengingatkan Periksa Dahak Dengan Kejadian Drop Out (Do) Pengobatan Tuberkulosis" (hal 176-184)

\begin{tabular}{|c|c|c|c|c|c|c|c|}
\hline \multirow{2}{*}{$\begin{array}{c}\text { Menginga } \\
\text { tkan } \\
\text { periksa } \\
\text { dahak }\end{array}$} & \multicolumn{2}{|c|}{$\begin{array}{l}\text { Drop } \\
\text { Out }\end{array}$} & \multirow{2}{*}{$\begin{array}{l}\text { Tot } \\
\text { al }\end{array}$} & \multirow{2}{*}{ OR } & \multicolumn{2}{|c|}{$99.00 \% \mathrm{CI}$} & \multirow[t]{2}{*}{$\mathrm{p}$} \\
\hline & $\mathrm{Ya}$ & $\begin{array}{l}\text { Tid } \\
\text { ak }\end{array}$ & & & Lower & Upper & \\
\hline Tidak & 26 & 14 & 40 & 2.600 & 1.167 & 5.792 & 0.018 \\
\hline $\mathrm{Ya}$ & 30 & 42 & 72 & & & & \\
\hline Total & 56 & 56 & 112 & & & & \\
\hline
\end{tabular}

Dari Tabel 1.1 menunjukkan hubungan faktor pelaksanaan tugas PMO mengingatkan periksa dahak dengan kejadian Drop Out didapatkan pengawas menelan obat (PMO), yang mengingatkan periksa dahak ulang penderita yang Drop Out adalah sebanyak 30 orang dan yang tidak Drop Out adalah sebanyak 42 orang. PMO yang tidak mengingatkan periksa dahak ulang dengan penderita yang Drop Out adalah sebanyak 26 orang dan yang tidak Drop Out sebanyak 14 orang.

Dilihat dari hubungan antara faktor pelaksanaan tugas mengingatkan PMO dengan kejadian DO menunjukan nilai $\mathrm{OR}=2.600, \quad 95 \% \quad$ CI $1.167-5792$. Dengan demikian dapat diartikan bahwa penderitaTB yang tidak diingatkan periksa dahak ulang oleh PMO memiliki resiko 2.600 kali lipat untuk menjadi DO dibanding penderita yang diingatkan oleh PMO, dan hubungan tersebut signifikan (bermakna).

Pelaksanaan tugas pengawas menelan obat (PMO) yang kurang optimal untuk mengingatkan penderita TB merupakan salah satu faktor yang dapat menjadikan pasien TB dalam keadaan DO. PMO sebagai ujung tombak penanganan TB diperlukan pengaturan tugas pedoman bagi PMO (Sari, 2017). Melalui pedoman PMO yang terarah menjadikan PMO lebih dapat menjalankan tugasnya secara optimal (Sari, 2018). Berdasarkan hasil penelitian menunjukan bahwa ada hubungan antara faktor pelaksanaan tugas mengingatkan pengawas menelan obat (PMO) dengan kejadian drop out (DO).

Dilihat dari hasil penelitian, PMO yang melakukan tugas mengingatkan penderita tuberculosis (TB) pada kelompok kasus dengan pasien DO adalah sebesar $53.6 \%$ dan yang tidak melakukan sebesar $46.4 \%$. sedangkan pada kelompok kontrol yang PMO yang mengingatkan untuk periksa dahak ulang penderita adalah sebesar $75 \%$ dan yang tidak 
mengingatkan sebesar 25\%. PMO mengingatkan penderita untuk periksa dahak ulang pada fase intensif dan fase lanjutan, kurang maksimalnya pelaksanaan tugas PMO untuk mengingatkan penderita untuk dahak ulang menjadi faktor yang memicu terjadinya DO pada penderita TB. Menurut Departemen Kesehatan RI (2007) bahwa salah satu tugas PMO sebagai salah satu komponen DOTS adalah mengingatkan penderita untuk periksa dahak ulang pada waktu yang telah ditentukan. sejalan dengan penelitian yang dilakukan oleh Jumaelah, et al (2012) dikatakan bahwa kinerja PMO mempunyai hubungan terhadap keberhasilan pengobatan, dengan kata lain bahwa PMO dengan kinerja yang kurang dapat berpengaruh terhadap kejadian DO.

Peneliti berasusmi bahwa pelaksanaan tugas mengingatkan periksa dahak ulang penderita TB oleh PMO menjadi faktor yang mempengaruhi terhadap kejadian DO penderita TB. Menurut Fox, 2012 kontak serumah pasien TB juga perlu untuk aktif memeriksakan dahak karena keluarga kontak serumah mempunyai resiko lebih tinggi tertular TB. Tugas PMO akan lebih maksimal apabila dilakukan dengan cara bertatap muka secara langsung dengan penderita TB, terlebih pendeita $\mathrm{TB}$ di Kota Tasikmalaya masih mengandalkan untuk diingatkan dalam pemeriksaaan dahak ulang oleh PMO. Jadi PMO yang tidak melaksanakan tugas mengingatkan penderita akan meningkatkan angka kejadian DO serta kesadaran dari penderita itu sendiri. Untuk PMO yang tidak melakukan tugas mengingatkan untuk periksa dahak ulang ini dikarenakan kurangnya pengetahuan PMO tentang tugas dan fungsinya sebagai orang yang mengawasi penderita dalam pengobatan sehingga perlu meningkatkan fungsi dari PMO dan kesadaran dari penderita TB itu sendiri.

\section{SIMPULAN DAN SARAN}

Berdasar hasil penelitian, PMO yang melakukan tugas mengingatkan penderita tuberculosis (TB) pada kelompok kasus dengan pasien DO adalah sebesar $53.6 \%$ dan yang tidak 
Nina Pamela Sari, Gandi Sukma Nugraha "Hubungan Tugas Pmo Dalam Mengingatkan Periksa Dahak Dengan Kejadian Drop Out (Do) Pengobatan Tuberkulosis" (hal 176-184)

melakukan sebesar 46.4\%. sedangkan pada kelompok kontrol yang PMO yang mengingatkan untuk periksa dahak ulang penderita adalah sebesar $75 \%$ dan yang tidak mengingatkan sebesar 25\%, sehingga diperlukan peran aktif dari programer TB, kader, PMO untuk lebih mengoptimalkan tugas PMO terutama dalam mengingatkan pasien TB periksa dahak ulang sebagai salah satu cara penanggulangan penularan TB

\section{DAFTAR PUSTAKA}

Arifin Zainal (2008) Dasar-Dasar Penulisan Karya Ilmiah Edisi ke empat Jakarta : Grasindo (hal 56)

Budiman, \& Riyanto, A (2013) Kapita Selekta Kuesioner Pengetahuan dan Sikap dalam Penelitian Kesehatan Jakarta: Salemba Medika

Danusantoso, H (2013) Buku Saku Ilmu Penyakit Paru Jakarta: EGC Djojodibroto, D (2009) Respirologi (Respiratory Medicine) Jakarta: EGC

Fox, G. J., Nhung, N. V., Sy, D. N., Lien, L. T., Cuong, N. K., Britton,
W. J., \& Marks, G. B. 2012. Contact investigation in households of patients with tuberculosis in Hanoi Vietnam: A prospective cohort study PLoS One 7(11) : e49880

Indonesian Ministry of Health 2013 Riset Kesehatan Dasar 2013 (Jakarta : BadanPenelitian dan Pengembangan Kesehatan Kementrian Kesehatan Republik Indonesia) p iii-xvi

Indonesian Ministry of Health 2016 Peraturan Menteri

Kesehatan Republik Indonesia nomor 67 tahun 2016 tentang Penanggulangan Tuberkulosis (Jakarta : Kementrian Kesehatan Republik Indonesia ) p 112-113 Indonesian Ministry of Health 2014 Pedoman Nasional Pengendalian Tuberkulosis (Jakarta : Kementrian Kesehatan Republik Indonesia) p1-5 614.542. Ind. P

Marilyn, M.F (2013) Keperawatan Keluarga Teori dan Praktik Edisi ke 5 Jakarta: EGC Muslihin, A (2012) Keperawatan Keluarga Yogyakarta: Gosyen Publishing Naga, S.S.(2012) Buku 
Nina Pamela Sari, Gandi Sukma Nugraha "'Hubungan Tugas Pmo Dalam Mengingatkan Periksa Dahak Dengan Kejadian Drop Out (Do) Pengobatan Tuberkulosis" (hal 176-184)

Panduan Lengkap Ilmu Penyakit Dalam Jogjakarta: DIVA press

Nizar, M (2017) Pemberantasan dan Penanggulangan Tuberkulosis Edisi Revisi Yogyakarta: Gosyen Publishing

Notoatmodjo, S (2010) Metodologi Penelitian Kesehatan Edisi Rev Jakarta: Renika Cipta

Nuraeni N, et al (2016) Community Health Nursing Bandung: Balatin Pratama

Sari NP, Juniarti N, Indrayani D, (2017) Development of Task Guidelines for Observer Tuberculisus A Literature Review. Retrieved from: https://www.researchgate. net/profile/Nina_Pamela_Sari2/pu bl ication/325430 010_Development_of_Task_Guid eli nes_for _Observer_Tuberculosis_A_Literature

$$
\begin{array}{lr}
- & \text { Review/links/5 } \\
\text { b0dbc2c0f7e9b1ed701208e/Devel } \\
\text { o } & \text { pment-of-Task- } \\
\text { Guidelines-for- } & \text { Observer } \\
\text {-Tuberculosis-A- } & \text { Literature- } \\
\text { Review.pdf } &
\end{array}
$$

Sari, NP, (2018), The Influence of Guidelines For TB Observer Task in Tamansari, Malaysian Journal of Medical Research, doi: 10.31674/mjmr.2018.v02i04.004 Vol. 2 (4) October 2018 p 32-38 Setawati \& Nurwani (2008) Asuhan Keperawatan Keluarga Konsep dan Aplikasi Kasus Jogjakarta: Mitra Cendika

Somantri (2012) Asuhan Keperawtan pada Klien dengan Gangguan Sistem Pernafasan Edisi 2 Jakarta: Salemba Medika Sugiyono (2012) Metodology Penelitian Kuantitatif Kualitatif Dan $R \& D$ disi ke - 17 Bandung: Alfabeta

Tabrani (2010) Ilmu Penyakit

Paru Jakarta: CV.Trans Info Media

Profil Kesehatan Jawa Barat.(2012) http://www.depkes.go.id/resource s/ download/Infodatin Tubekulosis Temukan Obat Sampai Sembuh, 2016 http://www.depkes.go.id/folder/vi e w/01/structure-publikasipusdatin-info-datin.html 
Jurnal Kesehatan Karya Husada, No 7 Vol 2 Tahun 2019

PISSN 2337649X/EISSN 2655-8874

Nina Pamela Sari, Gandi Sukma Nugraha "Hubungan Tugas Pmo Dalam Mengingatkan Periksa Dahak Dengan

Kejadian Drop Out (Do) Pengobatan Tuberkulosis" (hal 176-184)

Ghendis, et al. Hubungan

Antara Pengetahuan, Sikap dan

Dukungan Keluarga dengan

Kepatuhan Minum Obat pada

Pasien TB Paru di BKPM Pati

http://pmb.stikestelogorejo.ac.id/e

jo

urnal/index.php/ilmukeperawatan/

ar ticle/view/89

Pengobatan Pada Penderita TB Paru

di Balai Pengobatan Penyakit

Paru - Paru (BP4)

Salatiga.

http://lib.ui.ac.id/naskahringkas/2

015-09/S52672-

Lia\%20Alfiana\%20Fauz iah.

Octovianus Lapolalan dkk.

(2015).Analisis Faktor - factor

yang Berhubungan dengan

Kejadian Droup Out Penderrita

TB Paru di Puskesmas Kota

Sorong.https://www.google.co.id/

?g

ws_rd=cr,ssl\&ei=x2AaWbByjPe8 